
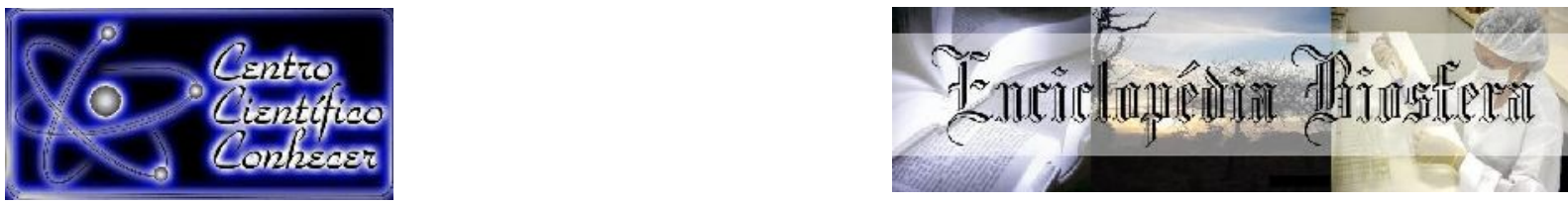

\title{
FLORESCIMENTO E FRUTIFICAÇÃO DE ACEROLEIRAS EM CULTIVOS ORGÂNICOS NO MUNICÍPIO DE PARNAÍBA, PIAUÍ, BRASIL
}

\author{
Idomar Fernandes Milindro ${ }^{1}$, Aurinete Daienn Borges do Val $^{2}$, Alan Lopes Souza ${ }^{1}$, \\ Monalisa Galeno da Costa Cunha ${ }^{1}$, Alex Carvalho Andrade ${ }^{2}$ \\ ${ }^{1}$ Engenheiros Agrônomos graduados na Universidade Estadual do Piauí-UESPI, \\ Parnaíba-PI, Brasil. \\ ${ }^{2}$ Professor(a) Doutor(a) do curso de Agronomia da Universidade Estadual do \\ Piauí - UESPI (aurineteval@uespi.phb.br) Parnaíba-PI, Brasil.
}

Recebido em: 04/10/2019 - Aprovado em: 30/11/2019 - Publicado em: 15/12/2019 DOI: 10.18677/EnciBio_2019B30

\begin{abstract}
A aceroleira possui importância econômica e social para o município de Parnaíba, PI, Brasil, onde a cultura está implantada em cerca de 240 ha e é cultivada em sistema orgânico. Objetivou-se com este trabalho avaliar o florescimento e a frutificação de aceroleiras da cv. BRS 366 - Jaburu e do clone CNPAT 13-02, em três diferentes épocas. O delineamento foi feito em dois pomares comerciais nos períodos compreendidos entre os meses de novembro-dezembro de 2017, fevereiro-março de 2017, e maio-junho de 2018. A cada ciclo de avaliação, foram selecionadas cinco plantas por genótipo, sendo que em cada planta marcou-se 40 botões florais, perfazendo um total de 200 plantas por genótipo. Foram estudados parâmetros relacionados ao florescimento e frutificação das aceroleiras. Os resultados obtidos permitiram concluir que algumas variáveis estudadas foram influenciadas pelo fator época. A cultivar BRS 366-Jaburu apresentou a maior porcentagem média de frutificação com $17,58 \%$, sendo que na época entre os meses maio-junho obteve-se a maior taxa de frutificação com $28,25 \%$. A duração média do ciclo da aceroleira desde a emissão do botão floral até a colheita do fruto verde, considerando as três épocas analisadas, foi de 22,42 dias. O menor intervalo de tempo entre a emissão do botão floral e a colheita do fruto verde ocorreu na época maio-junho com 21,96 dias.
\end{abstract}

RESUMO

PALAVRAS-CHAVE: BRS 366-Jaburu, BRS 235-Apodi, CNPAT 13-02,, , Malpighia emarginata DC., DITALPI.

\section{FLOWERING AND FRUITING OF BARBADOS CHERRY TREES IN ORGANIC CROPS OF THE MUNICIPALITY OF PARNAÍBA, PIAUÍ, BRAZIL}

\footnotetext{
ABSTRACT

The acerola tree has social-economic importance for the city of Parnaíba, PI, Brazil, where the crop is implanted in about 240 ha and is cultivated in an organic system. It was aimed with this work to evaluate the blooming and fruiting of acerola trees
} 
from cv. BRS 366 - Jaburu and the clone CNPAT 13-02 in three different periods. The design was made in two commercial orchards in the periods between November-December of 2017, February-March of 2018, and May-June of 2018. At each evaluation cycle five plants per genotype were selected, and in each plant was marked 40 flower buds, making a total of 200 per genotype. Were studied parameters related to the blooming and fruiting of the acerola trees. The obtained results allowed to conclude that some variables studied were influenced by the period factor. The cultivate BRS 366-Jaburu presented the highest average percentage of fruiting with $17.58 \%$, being that in the time between May-June the highest fruiting rate was obtained with $28.25 \%$. The average length of the acerola tree cycle from the flower bud emission until the green fruit harvest, considering the three analyzed seasons, was 22.42 days. The shortest time interval between floral bud and green fruit harvest occurred in the May-June season with 21.96 days.

KEYWORDS: BRS 366-Jaburu, BRS 235-Apodi, CNPAT 13-02, Malpighia emarginata DC, DITALPI.

\section{INTRODUÇÃO}

No Brasil, a acerola (Malpighia emarginata DC) está presente em todas as regiões, no entanto, é no Nordeste onde está concentrada a maior parcela da produção nacional ( CÁLGARO; BRAGA, 2012; CARDOSO et al, 2010; ADRIANO et al. 2011)). Na região, o cultivo da espécie passa por um processo de expansão com novas áreas sendo incorporadas aos sistemas produtivos da espécie (SIQUEIRA et al. 2011). Além do aumento do número de produtores e do aumento de área, o modelo de produção também apresenta mudanças uma vez que a adoção do sistema orgânico é cada vez mais comum em locais onde o objetivo é a produção de frutos para extração de vitamina $C$, por exemplo (MARTINS et al,2016).

Nas áreas de cultivo, a cultura possui uma importância socioeconômica, pois os plantios exigem a presença constante do agricultor e requerem mão de obra em quantidade suficiente para a realização dos tratos culturais e colheita, promovendo, assim, a permanência do trabalhador no meio rural.

Calgaro e Braga. (2012) e Pintos et al. (2012) relataram que a área de cultivo de acerola, no Brasil, é superior a 7.200 hectares, com produção destaque para a região Nordeste, que no ano de 2012 possuía aproximadamente 3.300 ha, sendo responsável pela maior parte da produção nacional (66\%).

O fruto, que é do tipo drupa e pode apresentar formatos que variam do arredondado ao cônico, possui grande importância nutricional, que fez da acerola uma fruta requisitada no mercado mundial de beneficiamento de polpa. (MACIEL et al, 2010; ASSIS et al., 2007). O grande potencial da acerola é a possibilidade de processamento, uma vez que pode ser consumida sob a forma de sucos, compotas, geleias, enriquecimento de sucos e alimentos dietéticos, na produção de alimentos nutracêuticos, como comprimidos ou cápsulas, empregados como suprimento alimentar, chás, bebida para esportistas, barra de cereais e iogurtes (CARPENTIERI-PÍPOLO et al., 2002; REIS et al., 2017).

No ano de 2016, em Parnaíba, no Piauí, a produtividade média obtida em cultivo orgânico irrigado foi de aproximadamente $56 \mathrm{t} / \mathrm{ha} \mathrm{ano}^{-1}$ (MARTINS et al., 
2016). No município, que possui clima do tipo AW' (BASTOS et al. 2005; MMA, 2006) e está localizado no litoral do Estado, a produção da acerola está concentrada no DITALPI - Distrito de Irrigação dos Tabuleiros Litorâneos do Piauí, que possui aproximadamente 240 ha cultivados com a espécie e reúne cerca de 40 produtores que exploram a aceroleira em sistema de produção orgânica e colhem de 10 a 12 safras por ano. Diferente das informações de Gomes et al., ( 2001) que relatam de 6 a 7 safras/ano na região de Jaboticabal, SP. A atividade, que está associada a uma cadeia produtiva intimamente relacionada à agroindústria de processamento da fruta, possibilita a geração de vários postos de trabalho ao longo das safras e a melhoria da qualidade de vida dos produtores.

As acerolas produzidas no DITALPI atendem a dois mercados, que são a fabricação de polpa de fruta congelada, cuja matéria-prima são os frutos maduros; e a produção de produtos farmacêuticos, que utiliza frutos ainda verdes para extração de vitamina C. Entre os genótipos cultivados pelos produtores parnaibanos os principais são a cultivar BRS 366-Jaburu e o clone CNPAT 13-02, também conhecido como BRS 235-Apodi.

Nas condições do norte do Piauí, a aceroleira exibe um ciclo produtivo caracterizado pelo florescimento, frutificação e, em seguida, por um repouso vegetativo, quando não há emissão de novos ramos e flores. Após esse período, cuja duração é em função das condições de manejo, climática e do genótipo, novo ciclo de produção é iniciado com a emissão de novos botões florais, abertura das flores e vingamento dos frutos. Os ramos em produção apresentam folhas, botões florais, flores abertas e frutos em diferentes estágios de desenvolvimento.

No Distrito, é comum os agricultores induzirem as plantas ao estresse hídrico, quando promovem a suspensão do fornecimento de água às plantas após o fim de uma safra. A prática tem como objetivos o aumento do número de botões florais, a uniformização do florescimento, frutificação e colheita (GUEDES et al, 2011).

Alguns autores relatam que as variações de componentes climáticos como a temperatura, umidade do ar, precipitação e ventos possam influenciar no crescimento, fenologia e produção da aceroleira, uma vez que a espécie é vulnerável a estas oscilações e tais mudanças afetam significativamente a duração dos estádios de florescimento e frutificação, e portanto a produção (CARPENTIERI-PÍPOLO et al., 2008; GUEDES et al., 2010; ALMEIDA et al., 2014; OLIVEIRA et al., 2015). Segundo Siqueira et al (2011), a produção das aceroleiras ao longo dos diferentes meses do ano, em um mesmo cultivo e sob as mesmas práticas culturais apresenta variações importantes. Vilhena e Augusto (2007) e Bezerra et al. (2017) afirmam que a população de insetos polinizadores também influencia a produção. De acordo com estes autores, as abelhas solitárias da tribo Centridini são as polinizadoras efetivas de $M$. emarginata,

A influência da variação climática sobre a produção das aceroleiras cultivadas em Parnaíba (PI) ainda não estão esclarecidas, e ainda não é possível avaliar se parâmetros como a duração dos períodos de florescimento, frutificação, desenvolvimento dos frutos e a sazonalidade dos picos de produção são influenciados pelas variações climáticas que ocorrem e diferentes épocas do ano no município. 
Diante do exposto objetivou-se estudar o comportamento do florescimento e frutificação de dois genótipos de aceroleiras em três épocas com diferentes condições climáticas.

\section{MATERIAL E MÉTODOS}

As avaliações foram feitas em dois pomares localizados no DITALPI $\left(2^{\circ}\right.$ $55^{\prime} \mathrm{S}, 41^{\circ} 50^{\prime} \mathrm{W}$ e $40 \mathrm{~m}$ de altitude) distantes entre si cerca de $3 \mathrm{~km}$. As plantas selecionadas, oriundas de mudas enxertadas e em produção há cinco anos, localizam-se nas áreas centrais dos pomares, onde o espaçamento utilizado é de cinco metros entre linhas e três metros entre plantas. Todo o sistema de manejo dessas plantas baseia-se na produção orgânica e a colheita é feita de forma manual. O método de irrigação utilizado é o de micro aspersão.

$O$ delineamento experimental utilizado foi o de blocos casualizados, em parcelas subdivididas com cinco repetições. Cada planta constituiu um bloco, sendo que os genótipos constituíram as parcelas principais e as épocas de avaliação, as subparcelas. Para cada época e área foram marcados 200 botões por genótipo, distribuídos em cinco plantas distintas. Os dados foram submetidos à análise de variância e ao teste de Tukey ao nível de significância de $5 \%$, utilizando o programa Sisvar (FERREIRA, 2011).

O início do estudo se deu em novembro de 2017, e as épocas de avaliação estavam compreendidas entre dois meses. Assim, a primeira, segunda e terceira épocas abrangeram, respectivamente, os meses de novembro e dezembro de 2017, fevereiro e março de 2018 e maio e junho de 2018. Na Tabela 1 estão apresentadas as médias de temperatura, precipitação, umidade relativa do ar e velocidade do vento registrados nas épocas de avaliação. Os dados foram obtidos na estação meteorológica da Embrapa Meio Norte, instalada a cerca de 10 km dos locais de avaliação.

TABELA 1 - Média das temperaturas máxima, mínima e média, volume acumulado de água por precipitação, médias da umidade relativa do ar e da velocidade do vento referentes às três épocas de avaliação nas condições de Parnaíba, PI, Brasil.

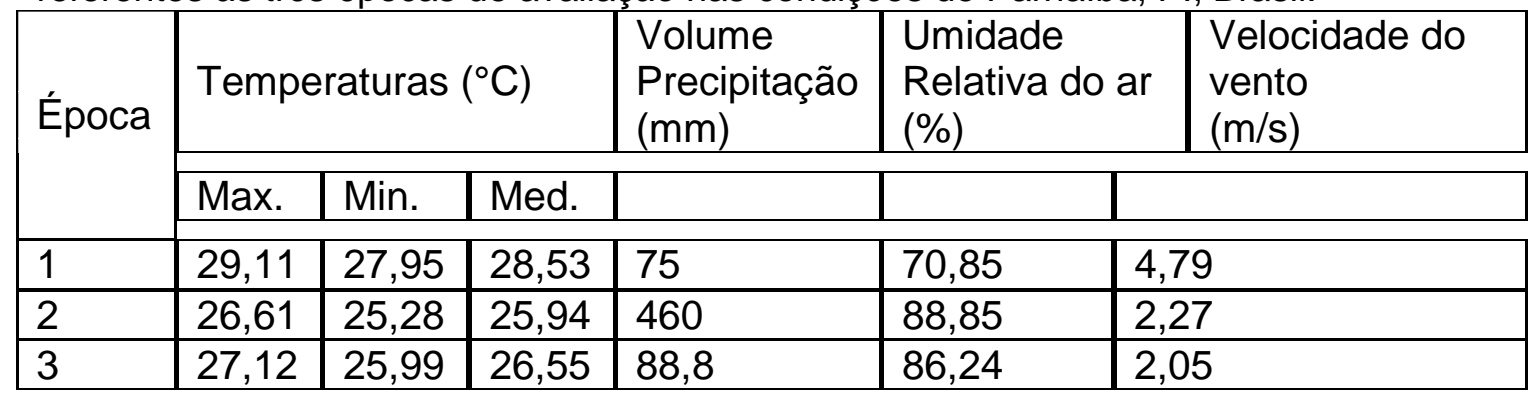

Em todos os períodos de avaliação, as leituras ocorreram diariamente desde a marcação dos botões florais até a colheita dos frutos.

Os genótipos avaliados foram a cultivar BRS 366-Jaburu e o clone CNPAT 13-02. Para cada época e pomar, foram marcados 200 botões florais intumescidos por genótipo, distribuídos em dez ramos aleatórios, localizados nos quatros quadrante da copa. Foram marcadas cinco plantas/genótipo, conforme metodologia adotada por (CARPENTIERI-PÍPOLO et al., 2008). Em cada planta avaliou-se parâmetros relacionados ao florescimento e características da 
produção. Procedeu-se a marcação dos botões com o auxílio de uma fita de cetim, identificada com etiquetas plastificadas que continham as informações de identificação do botão floral, da planta e do genótipo.

As características do florescimento estudadas foram: queda de botão floral; intervalo, em dias, entre a emissão do botão floral e antese; número de flores abertas, e queda de flor. Avaliou-se os seguintes parâmetros de frutificação: intervalo, em dias, entre a abertura da flor e o vingamento do fruto; pegamento de frutos; queda do fruto verde; intervalo, em dias, entre a emissão do botão floral e a colheita de frutos verdes; percentagem de frutos colhidos; porcentagem de frutos vingados e frutificação média. A colheita ocorreu quando os frutos estavam no padrão de tamanho e cor utilizado pelos produtores.

Em cada época foram marcados 400 botões para cada genótipo. Para tal, considerou-se os dois pomares. A porcentagem de flores abertas, frutos vingados e frutos colhidos foram obtidos a partir da relação entre o número de flores marcadas, polinizadas naturalmente, e o número de frutos verdes colhidos. A frutificação média foi obtida a partir da média dos frutos colhidos, nas três épocas de avaliação, para cada genótipo.

\section{RESULTADOS E DISCUSSÃO}

Os dados referentes à taxa de frutificação estão apresentados na Tabela 2. Entre novembro e dezembro de 2016 houve variação de 3,25\% a 6,0\% para o clone CNPAT 13-02 e cultivar BRS 366-Jaburu, respectivamente. Observou-se que na época 2 houve aumento no pegamento dos frutos em ambos os genótipos, com dados de 21,75\% para CNPAT $13-02$ e 18,50\% para BRS 366-Jaburu. Na terceira época, observou-se um comportamento diferente, com queda na taxa de pegamento para o clone CNPAT 13-02 e aumento para a cultivar BRS 366-Jaburu (Tabela 2).

TABELA 2 - Número total e porcentagem de flores em antese, frutos vingados, frutos colhidos e frutificação média em diferentes genótipos de aceroleiras durante três períodos de produção. Parnaíba- PI, Safra 2017/2018.

\begin{tabular}{|c|c|c|c|c|c|c|c|c|c|}
\hline \multirow{2}{*}{ Genótipo } & \multirow{2}{*}{ Época } & \multirow[t]{2}{*}{ NBT } & \multicolumn{2}{|l|}{ FA } & \multicolumn{2}{|l|}{ VF } & \multicolumn{2}{|c|}{ FC } & \multirow[t]{2}{*}{$\begin{array}{l}\text { Frutificação } \\
\text { média (\%) }\end{array}$} \\
\hline & & & $n^{\circ}$ & $\%$ & $n^{\circ}$ & $\%$ & $n^{\circ}$ & $\%$ & \\
\hline \multirow{3}{*}{$\begin{array}{l}\text { CNPAT- } \\
13-02\end{array}$} & 1 & 400 & 261 & 65,2 & 89 & 22,5 & 13 & 3,25 & \multirow{3}{*}{12} \\
\hline & 2 & 400 & 350 & 87,5 & 281 & \begin{tabular}{|l}
70,2 \\
\end{tabular} & 87 & 21,7 & \\
\hline & 3 & 400 & 315 & 78,7 & 180 & \begin{tabular}{|l}
45,0 \\
\end{tabular} & 44 & 11,0 & \\
\hline \multirow{3}{*}{$\begin{array}{l}\text { BRS-366 } \\
\text { Jaburu }\end{array}$} & 1 & 400 & 304 & 76,0 & 133 & \begin{tabular}{|l|}
33,2 \\
\end{tabular} & 24 & 6,0 & \multirow{3}{*}{17,58} \\
\hline & 2 & 400 & 348 & 87,0 & 235 & \begin{tabular}{|l}
58,7 \\
\end{tabular} & 74 & 18,5 & \\
\hline & 3 & 400 & 272 & 68,0 & 228 & 57,0 & 113 & 28,2 & \\
\hline
\end{tabular}

*NBT- Número de botões florais; FA- Flor aberta; VF- Vingamento de fruto; FC - Frutos colhidos. 
A frutificação média apresentada na Tabela 2 foi contrastante com a observada por Lopes et al. (2001) em um trabalho feito em Visconde do Rio Branco, MG, em que e os valores variaram entre $15,2 \%$ a $31,85 \%$. Essa diferença na variação do desenvolvimento dos frutos pode ser atribuída à população dos insetos polinizadores e à resposta dos genótipos às variação climáticas ao longo do tempo (CARPENTIERI-PÍPOLO et al., 2008).

Uma das hipóteses para os baixos índices de produção da aceroleira é o fato da cultura apresentar problemas com o pegamento natural dos frutos, apesar da abundância de flores indicando uma possível deficiência na polinização natural (BARBOZA et al., 1996). Outro fator que pode ter contribuído para a baixa taxa de frutificação foi a condição ambiental desse período que não foi favorável à visitação dos insetos polinizadores, principais agentes polinizadores das aceroleiras, uma vez que a produção de acerola pode aumentar consideravelmente quando as flores são visitadas por abelhas (OLIVEIRA et al., 2015).

Siqueira et al. (2011), em estudo no Nordeste do Brasil, registraram que na ausência da atividade dos polinizadores não há sucesso reprodutivo, porém, com a presença dos visitantes florais a taxa de frutificação oscilou de $23 \%$ a $53 \%$ e que as oscilações de produção ocorrem devido às condições climáticas não favoráveis. Guedes et al. (2011) relataram que a partir da autopolinização espontânea, a frutificação foi de apenas $6,7 \%$. Além das condições ambientais, essa oscilação de produção pode estar relacionada com as características genéticas dos indivíduos (PAIVA, 2003).

De acordo com a análise dos dados, não houve diferença entre os genótipos com relação aos parâmetros relacionados ao florescimento e colheita, com $P>0,05$, conforme apresentado na Tabela 3.

TABELA 3 - Número médio de botões florais abortados e do tempo de duração das etapas de botão floral, antese, vingamento do fruto e colheita de frutos verdes de aceroleiras de diferentes genótipos. Parnaíba-PI, Safra 2017/2018

\begin{tabular}{|l|l|l|l|l|}
\hline Genótipos & $\begin{array}{l}\text { Número de } \\
\text { botões } \\
\text { florais } \\
\text { abortados }\end{array}$ & $\begin{array}{l}\text { Botão } \\
\text { floral à flor } \\
\text { aberta } \\
\text { (dias) }\end{array}$ & $\begin{array}{l}\text { Botão floral } \\
\text { ao vigamento } \\
\text { do fruto } \\
\text { (dias) }\end{array}$ & $\begin{array}{l}\text { Botão floral à } \\
\text { colheita do } \\
\text { fruto verde } \\
\text { (dias) }\end{array}$ \\
\hline CNPAT 13-02 & 9,10 a & 7,87 a & 10,41 a & 22,97 a \\
\hline $\begin{array}{l}\text { BRS-366 } \\
\text { Jaburu }\end{array}$ & 9,17 a & 7,99 a & 10,00 a & 21,86 a \\
\hline
\end{tabular}

* Médias seguidas da mesma letra na coluna não diferem entre si pelo teste de Tukey a $5 \%$ de probabilidade.

$\mathrm{Na}$ Tabela 4 estão apresentados os resultados da avaliação dos parâmetros de florescimento e colheita em diferentes épocas. Com exceção da duração do período compreendido entre o botão floral à colheita do fruto verde, todos os demais parâmetros apresentaram diferenças significativas em umas das épocas de avaliação. 
TABELA 4 - Médias do número de botões florais abortados e do tempo de duração das etapas de botão floral à antese, ao vingamento do fruto e à colheita de frutos verdes, em três épocas de produção e colheitas de plantas de aceroleiras. Parnaíba-PI, Safra 2017/2018.

\begin{tabular}{|l|l||l|l|l|}
\hline Época & $\begin{array}{l}\text { Número de } \\
\text { botões florais } \\
\text { abortados }\end{array}$ & $\begin{array}{l}\text { Botão floral à } \\
\text { flor aberta } \\
\text { (dias) }\end{array}$ & $\begin{array}{l}\text { Botão floral } \\
\text { ao } \\
\text { vigamento } \\
\text { do fruto } \\
\text { (dias) }\end{array}$ & $\begin{array}{l}\text { Botão floral à } \\
\text { colheita do } \\
\text { fruto verde } \\
\text { (dias) }\end{array}$ \\
\hline 1 & $11,60 \mathrm{a}$ & $7,56 \mathrm{~b}$ & $10,50 \mathrm{a}$ & $22.53 \mathrm{a}$ \\
\hline 2 & $5,25 \mathrm{~b}$ & $9,25 \mathrm{a}$ & $11,52 \mathrm{a}$ & $22,75 \mathrm{a}$ \\
\hline 3 & $10,55 \mathrm{a}$ & $6,98 \mathrm{~b}$ & $8,60 \mathrm{~b}$ & $21,97 \mathrm{a}$ \\
\hline
\end{tabular}

* Médias seguidas da mesma letra na coluna não diferem entre si pelo teste de Tukey a $5 \%$ de probabilidade

O intervalo entre a emissão do botão floral até a colheita do fruto verde não variou $(P>0,05)$ entre as épocas analisadas, com média de 22,42 dias. Icuma et al. (2003) observaram que do aparecimento do botão floral ao amadurecimento do fruto decorreram de 28 a 32 dias e que até o $18^{\circ}$ dia os frutos estavam totalmente verdes. Barboza et al. (1996), descreveram que, do florescimento à colheita, o período variou de 20 a 25 dias, resultados que corroboram com os encontrados neste trabalho.

Informações relativas ao florescimento e frutificação da aceroleira são importantes para que o produtor organize a execução de práticas culturais e possibilite estimar a produção, entender a sazonalidade dos picos de produção, que façam previsão da época de colheita e da comercialização, e por fim, um planejamento financeiro da atividade.

O estádio de botão floral à antese das flores foi maior $(\mathrm{P}<0,05)$ no período compreendido entre fevereiro e março, com duração média de 9,25 dias (Tabela 4). Adriano e Leonel (2012), trabalhando com a cultivar de acerola "Oliver", descreveram que o estádio de botão floral durou entre 4,09 e 3,88 dias nos ciclos de setembro e janeiro, respectivamente, nas condições ambientais de BotucatuSP.

No presente trabalho, o maior tempo observado para esse estádio se deve ao fato de que os botões foram marcados e avaliados antes da expansão do pedúnculo floral..

Alguns autores mostram em resultados obtidos em seus trabalhos que o tempo compreendido entre o aparecimento do botão floral e a antese é de sete dias, em média. (CARPENTIERI-PÍPOLO et al., 2008; RITZINGER; RITZINGER, 2011). Souza et al. (2017), avaliando a evolução do ciclo reprodutivo desde a emissão do botão floral a antese das flores, observaram que o tempo compreendido foi de 9,33 dias.

Observou-se menor queda dos botões florais $(P<0,05)$ no período referente à época 2 (Tabela 4 ). As maiores quedas entre os meses de novembrodezembro podem estar relacionadas à maior velocidade média do vento, além da baixa umidade do ar e elevadas temperaturas (Tabela 1), que podem promover a 
desidratação das estruturas florais, ocasionando quedas. Adriano e Leonel (2012) observaram alto índice de queda de botões $(20,5 \%)$, sendo que a taxa média de queda do botão floral no presente trabalho foi de $22,82 \%$.

A duração em dias do botão floral ao vingamento do fruto foi maior $(P<0,05)$ em novembro-dezembro e fevereiro-março em relação a maio-junho, com média geral de 10,21 (Tabela 4). Carpentieri-Pípolo et al. (2008), em seu trabalho apresentaram que a média do intervalo entre o botão floral ao vigamento do fruto foi de 14,91 dias.

Entre todas as variáveis estudadas, duas apresentaram interação significativa entre genótipo e época. Foram elas: tempo médio ,em dias, entre a abertura da flor e vingamento do fruto e queda de flores abertas. Na Tabela 5 é apresentada a interação entre os genótipos e épocas para o parâmetro intervalo da antese ao vingamento do fruto.

TABELA 5 - Tempo médio, em dias, compreendido entre abertura da flor e o vingamento dos frutos em aceroleiras de diferentes genótipos em três épocas de produção. Parnaíba-PI, Brasil. Safra 2017/2018.

\begin{tabular}{|l||l|l|l|l|}
\hline \multirow{2}{*}{ Genótipos } & \multicolumn{2}{|l|}{ Épocas } & \multirow{2}{*}{ Médias } \\
\cline { 2 - 4 } & 1 & 2 & 3 & \\
\hline CNPAT 13-02 & $2,83 \mathrm{~A} \mathrm{a}$ & $2,07 \mathrm{~B} \mathrm{a}$ & $2,37 \mathrm{AB} \mathrm{a}$ & 2,42 \\
\hline $\begin{array}{l}\text { BRS 366- } \\
\text { Jaburu }\end{array}$ & $2,00 \mathrm{~B} \mathrm{a}$ & $2,44 \mathrm{~B} \mathrm{a}$ & $1,42 \mathrm{~A} \mathrm{~b}$ & 2,15 \\
\hline Médias & 2,72 & 2,25 & 1,89 & \\
\hline
\end{tabular}

*Médias seguida de letras maiúsculas iguais na linha e letras minúsculas iguais na coluna não diferem entre si pelo teste Tukey a $5 \%$ de probabilidade.

Para o clone CNPAT 13-02 observou-se um menor $(P<0,05)$ intervalo da antese das flores ao fruto nas duas últimas épocas, fevereiro-março e maio-junho, necessitando de 2,07 e 2,37 dias respectivamente para ocorrer o pegamento de frutos. Na comparação entre genótipos, apenas a última época apresentou menor intervalo $(P<0,05)$ entre a abertura das flores à frutificação das plantas do genótipo BRS 366-Jaburu (Tabela 5).

Adriano e Leonel (2012), estudando os estádios fenológicos da aceroleira, reportam que a duração em dias da antese da flor ao vingamento do fruto variou de 4,34 dias na época de janeiro e 5,66 dias em setembro Carpentieri-Pípolo et al. (2008), observaram que o tempo de duração dessa fase variou entre 3,4 a 6,3 dias, dependendo do cultivar e da época de avaliação.

Assim como nos trabalhos acima citados, as variações das condições climáticas influenciam os eventos de florescimento e frutificação das aceroleiras do DITALPI no sentido de prolongar ou diminuir a duração de cada fase.

Quando estudado parâmetros de florescimento dos genótipos nas três épocas, pode-se constatar que a queda das flores foi mais acentuada $(P<0,05)$ para o genótipo CNPAT 13-02 no último período de avaliação. Entre as épocas observadas, a menor queda foi observada no segundo ciclo de avaliação (Tabela $6)$. 
TABELA 6 - Valor médio do número de flores abortadas em plantas de genótipos de aceroleiras em três épocas de produção no município de Parnaíba- PI, Brasil. Safra $2017 / 2018$

\begin{tabular}{|l|l|l|l|l|}
\hline \multirow{2}{*}{ Genótipos } & \multicolumn{2}{|l|}{ Época } & \multirow{2}{*}{ Médias } \\
\cline { 2 - 4 } & 1 & 2 & 3 & \\
\hline CNPAT 13-02 & $17,3 \mathrm{Ba}$ & $9,2 \mathrm{Ca}$ & $26,9 \mathrm{Aa}$ & 17,8 \\
\hline BRS 366-Jaburu & $17,1 \mathrm{Aa}$ & $11,6 \mathrm{Aa}$ & $15,9 \mathrm{Ab}$ & 14,8 \\
\hline Médias & 17,2 & 10,4 & 21,4 & \\
\hline
\end{tabular}

*Médias seguidas de letras maiúsculas iguais na mesma linha e letras minúsculas iguais na mesma coluna não diferem entre si pelo teste Tukey a $5 \%$ de probabilidade.

$\mathrm{Na}$ literatura não há relatos do efeito de altas temperaturas no abortamento de flores de acerola, entretanto o que se observou foi que a quantidade de quedas de novembro a dezembro de 2017 coincidiu com as menores porcentagens de frutificação para os dois genótipos avaliados.

A produção excessiva de flores é uma estratégia de sobrevivência da espécie, supondo que a planta que produz muitas flores teoricamente produzirá vários frutos. No entanto, muitas dessas flores são abortadas no início da formação para que a planta possa estabelecer condições fisiológicas de sustentar e garantir a maturidade de todas as sementes (PES; ARENHARDT, 2015). De acordo com Guedes et al. (2011), a abundância em flores não garante boa produção nos casos em que o nível populacional dos insetos polinizadores for pequeno e insuficiente para promover a polinização.

A maior queda de flores $(P<0,05)$ para o genótipo CNPAT 13-02 ocorreu entre maio e junho, com média de 26,9 (Tabela 6). O problema pode estar na polinização, cujo processo depende principalmente de insetos polinizadores com destaque para abelhas do gênero Centris spp., uma vez que nesse caso o vento é um agente ineficaz no processo de polinização da espécie, pois o pólen da aceroleira é pegajoso, pesado e denso, fácil de ser aderido ao corpo do inseto (RITZINGER; RITZINGER, 2011; SIQUEIRA et al, 2011).

Em média, a maior quantidade de botões florais abortados foi verificada entre novembro e dezembro. Esse comportamento pode estar relacionado à maior velocidade do vento, que influenciou de forma significativa para essas quedas. $A$ quantidade de botões abortados entre maio e junho não diferiu da primeira época $(P>0,05)$, enquanto que a menor média de quedas foi observada entre fevereiro e março (Tabela 7).

TABELA 7 - Velocidade média dos ventos em diferentes meses, queda de botões florais e de flores de aceroleiras abortados em três épocas no município de Parnaíba- PI, nas condições de Parnaíba- PI, Brasil. Safra 2017/2018.

\begin{tabular}{|l|l|l|l|}
\hline Épocas & Velocidade do vento $(\mathrm{m} / \mathrm{s})$ & $\begin{array}{l}\text { Número de botões florais } \\
\text { abortados }\end{array}$ & Queda de flor \\
\hline 1 & 4,79 & $11,60 \mathrm{a}$ & $17,20 \mathrm{a}$ \\
\hline 2 & 2,27 & $5,25 \mathrm{~b}$ & $10,40 \mathrm{~b}$ \\
\hline 3 & 2,05 & $10,55 \mathrm{a} \mathrm{b}$ & $21,40 \mathrm{a}$ \\
\hline
\end{tabular}

*Médias seguidas da mesma letra na coluna não diferem entre si pelo teste de Tukey a 5\% de probabilidade. 
Manica et al. (2003) reportam que tanto a planta como os frutos têm sido muito prejudicados quando a aceroleira é plantada em áreas de ventos intensos. Os autores recomendam que as plantas sejam podadas e conduzidas com altura ao redor de 2,5 a 3,2 metros e plantios com presença de quebra-ventos para criar melhores condições para as plantas em termos de crescimento, produção e na prevenção e controle de algumas doenças e pragas.

Para a queda de flores, na época de maio e junho verificou-se a maior média de quedas de flores em antese. A queda de flores abertas está relacionada principalmente à ausência de insetos polinizadores, à ineficiência de vento em transportar grãos de pólens e à deficiência hídrica.

\section{CONCLUSÕES}

Constatou-se que a cultivar BRS 366-Jaburu apresentou precocidade para antese e vingamento de fruto. O florescimento e frutificação de aceroleiras são influenciados pelo genótipo e condições climáticas, uma vez que as variáveis número de botões florais abortados, tempo de duração das etapas de botão floral à antese e botão floral ao vingamento do fruto apresentaram comportamentos variados. Fatores climáticos como o vento podem interferir na queda de produção dos pomares, uma vez que contribuem com a queda de flores.

\section{AGRADECIMENTOS}

À FUESPI - Fundação Universidade Estadual do Piauí pela concessão de bolsas de iniciação científica através do programa PIBIC - UESPI.

\section{REFERÊNCIAS}

ADRIANO, E.; LEONEL, S. Fenologia da aceroleira cv. Olivier em JunqueirópolisSP. Revista Brasileira de Fruticultura, v. 34, n. 2, p. 469-474, 2012. Disponível em:

http://www.scielo.br/scielo.php?pid=S01009452012000200020\&script=sci abstract \&tlng=pt DOI: http://dx.doi.org/10.1590/S0100-29452012000200020. Acesso em $12 / 09 / 2019$

ALMEIDA, G.F. de; AGUIAR, C.M.L.; SILVA, M.; SANTOS, R. M. Floração e frutificação da aceroleira (Malphigia emarginata DC.) em uma área no semiárido brasileiro. Magistra,v.26, n.2, p.241-247,2014.

Disponível em:

https://magistraonline.ufrb.edu.br/index.php/magistra/article/view/459/356 Acesso em: $25 / 04 / 2019$

ASSIS, S.A. de; FERNANDES, P. F.; MARTINS, A.B.G.; OLIVEIRA, O.M.M.de F. Acerola: importance, culture conditions, production and biochemical aspects.

Fruits, v. 63, n. 2, p. 93-10, 2007 Disponível em: http://www.fruits-journal.org DOI: http://dx.doi.org/10.1051/fruits:2007051 Acesso em 12/09/2019

BARBOZA, S.B.S.C.; TAVARES, E.D.; MELO, M.B. de. Instruções para o cultivo da acerola. Aracaju: Embrapa CPATC, 1996. 42p. ( EMBRAPA - CPATC. Circular 
Técnica, 6).Disponível em:

https://ainfo.cnptia.embrapa.br/digital/bitstream/item/44461/1/CPATC-

DOCUMENTOS-6-INSTRUCOES-PARA-O-CULTIVO-DA-ACEROLA-FL-

13124.pdf Acesso em: 25/04/2019

BASTOS, E.A.; RODRIGUES, B.H.N.; ANDRADE JÚNIOR, A. S. de; MEDEIROS, R.M. de. Boletim agrometeorológico do ano de 2005 para o município de

Parnaíba, PI. Teresina: Embrapa Meio Norte, 2005. 30p. (Documento 131Embrapa Meio Norte). Disponível em

https://ainfo.cnptia.embrapa.br/digital/bitstream/item/37225/1/Doc131.pdf Acesso em 25/10/2019

BEZERRA, A. dos S.; LEITE, J.L.N.; SILVA, K. R. da; OLIVEIRA, I.V. de; MELLO, A.H.de. Produção de mudas de acerola (Malpiguia emarginata D.C.) pelo método de enxertia em topo por garfagem em fenda cheia. Revista Agroecossistemas, v.9, n.1, p. 251-260, 2017.

Disponível em:

https://periodicos.ufpa.br/index.php/agroecossistemas/article/view/4775/4405 DOI: http://dx.doi.org/10.18542/ragros.v9i1.4774 Acesso em 15/08/2019

CALGARO, M.; BRAGA, M.B. A cultura da acerola. Brasília-DF: Embrapa. 2012. 144p. (Coleção Plantar; 69). Disponível em:

https://ainfo.cnptia.embrapa.br/digital/bitstream/item/128278/1/PLANTAR-Acerolaed03-2012.pdf Acesso em: 28/04/2019

CARPENTIERI-PÍPOLO, V.; NEVES, C. S. V. J.; BRUEL, D. C.; SOUZA, S. G. H. de; GARBÚGLIO, D. D. Frutificação e desenvolvimento de frutos de aceroleira no Norte do Paraná. Ciência Rural, v.38, n.7, p.1871-1876, 2008.

Disponível em: http://www.scielo.br/pdf/cr/v38n7/a11v38n7.pdf DOI:

10.1590/S0103-84782008000700011 Acesso em: 28/04/2019

CARPENTIERI-PÍPOLO, V.; PRETE, C. E. C.; GONZALEZ, M. G. N.; POPPER, I. O. Novas cultivares de acerola (Malpighia emarginata DC): UEL 3 - Dominga, UEL 4 - Lígia e UEL 5 - Natália. Revista Brasileira de Fruticultura, v. 24, n. 1, p. 124126, 2002. Disponível em: http://www.scielo.br/scielo.php?pid=S010029452002000100027\&script=sci_abstract\&tIng=pt DOI:

http://dx.doi.org/10.1590/S0100-29452002000100027. Acesso em: 28/04/2019

FERREIRA, D. F. Sisvar - a computer statistical analysis system. Ciência e Agrotecnologia, v.35, n 6, p.1039-1042, 2011.

Disponível em: http://www.scielo.br/scielo.php?pid=S1413-

$70542011000600001 \&$ script $=$ sci abstract\&tlng=pt

DOI: http://dx.doi.org/10.1590/S1413-70542011000600001. Acesso em:

$21 / 07 / 2019$ 
GUEDES, R. da S.; ZANELLA, F. C. V.; MARTINS, C. F.; SCHLINDWEIN, C. Déficit de polinização da aceroleira no período seco, no semiárido paraibano. Revista Brasileira de Fruticultura, v. 33, n. 2, p. 465-471, 2011.

Disponível em: http://www.scielo.br/scielo. php?pid=S010029452011000200017\&script=sciabstract\&tlng=pt DOI: http://dx.doi.org/10.1590/S0100-29452011005000060. Acesso em: 21/07/2019

GOMES, J. E. ; PAVANI, M. do C. M. D. ; PERECIN, D. ; MARTINS, A. B. G. Morfologia floral e biologia reprodutiva de genótipos de aceroleira. Scientia Agrícola, v. 58, n. 3, p. 519-523, 2001. Disponível em http://www.scielo.br/pdf/sa/v58n3/a13v58n3.pdf DOI: 10.1590/S010390162001000300013 Acesso em: 22/07/2019

ICUMA, I. M.; FIORAVANÇO, J. C.; PAIVA, J. R. de; PAIVA, M. C.; JUNQUEIRA, N. T. V. In: MANICA, I (Org.) Acerola: Tecnologia de produção, pós-colheita, congelamento, exportação, mercados. Porto Alegre: Cinco Continentes, 2003. $394 p$.

MARTINS, É. de A.; CAMPOS, R.T.; CAMPOS, K.C; ALMEIDA, C. de S. Rentabilidade da produção de acerola orgânica sob condição determinística e de risco: estudo do distrito de irrigação Tabuleiro Litorâneo do Piauí. Revista de Economia e Sociologia Rural, v. 54, n. 01, p. 009-028, 2016. Disponível em: http://www.scielo.br/scielo.php?pid=S0103- 20032016000100009HYPERLINK "http://www.scielo.br/scielo.php?pid=S0103-

20032016000100009\&script=sci_arttext"\&HYPERLINK "http://www.scielo.br/scielo.php?pid=S0103$20032016000100009 \&$ script=sci_arttext"script=sci_arttext DOI: http://dx.doi.org/10.1590/1234-56781806-9479005401001 Acesso em: 22/07/2019

MACIEL, M.I.S.; MÊLO, E.; LIMA,V. SOUZA, K.A.; SILVA, W. Caracterização físico-química de frutos de genótipos de aceroleira (Malpighia emarginata D.C.). Ciência e Tecnologia de Alimentos, v. 30, n. 4, p.865-869, 2010. Disponível em: http://www.scielo.br/pdf/cta/v30n4/v30n4a05.pdf DOI: http://dx.doi.org/10.1590/S0101-20612010000400005 Acesso em: 22/07/2019

MMA - Ministério do Meio Ambiente. Caderno da região hidrográfica do Parnaíba. Brasília: MMA. 2006. 184p. Disponível em:

https://www.mma.gov.br/estruturas/161/_publicacao/161_publicacao03032011023 605.pdf Acesso em 25/10/2019

OLIVEIRA, J. E. M. de; NICODEMO, D.; OLIVEIRA, F. F. de. Contribuição da polinização entomófila para a produção de frutos de aceroleira. Pesquisa Agropecuária Tropical, v. 45, n. 1, 2015. Disponível em: 
http://www.scielo.br/pdf/pat/v45n1/1983-4063-pat-45-01-0056.pdf DOI: http://dx.doi.org/10.1590/1983-40632015v4529199. Acesso em: 12/09/2019

PAIVA, J.R. de. Cultivares e Melhoramento Genético. In: Manica, Ivo. (Org.). Acerola: tecnologia de produção, pós-colheita, congelamento, exportação, mercados. Porto Alegre, RS: Cinco Continentes, p. 69-88. 2003.

PES, L. Z.; ARENHARDT, M. H.. Fisiologia vegetal. Santa Maria: Universidade Federal de Santa Maria, 2015. 81p.

Disponível em: https://www.ufsm.br/unidades-universitarias/ctism/cte/wpcontent/uploads/sites/413/2018/11/09 fisiologia vegetal.pdf Acesso em: 22/06/2019

PINTO, L. de B.; LOURENZANI, A.E.B.S.; LOURENZANI, W.; MOCHIUTI, J.C. Aspectos históricos e organizacionais da agricultura familiar no desenvolvimento da região Nova Alta Paulista. Revista Brasileira de Gestão e Desenvolvimento Regional, v. 8, n. 2, p. 130-150, 2012. Disponível em: https://repositorio.unesp.br/bitstream/handle/11449/73438/2-s2.084863851589.pdf?sequence $=1$ Acesso em: 15/08/2019

REIS, D.S.; FIGUEIREDO NETO, A.; FERRAZ, A.de V.; FREITAS, S.T. de. Produção e estabilidade de conservação de farinha de acerola desidratada em diferentes temperaturas. Brazilian Journal of Food Technology, v. 20, p. 1 -7, 2017. Disponível em: http://www.scielo.br/pdf/bjft/v20/1981-6723-bjft-198167238315.pdf DOI: http://dx.doi.org/10.1590/1981-6723.8315 Acesso em: $12 / 09 / 2019$

RITZINGER, R.; RITZINGER, C.H.S.P. Acerola. Informe Agropecuário. v. 32, n. 264, p. 17-25, 2011. Disponível em:

https://ainfo.cnptia.embrapa.br/digital/bitstream/item/54086/1/Acerola-RITZINGERRogerio.pdf Acesso em: 15/08/2019

SIQUEIRA, K.M.M de; FEITOSA, C.M..; PIEDADE; L.H.K.; TORRES,L.C. Estudo comparativo da polinização em variedades de aceroleiras (Malpighia emarginata DC, Malpighiaceae. Revista Caatinga, v. 24, n. 2, p. 18-25, 2011. Disponível em: http://www.redalyc.org/articulo.oa?id=237117605003 Acesso em: 22/06/2019

SOUZA, F. de F.; DEON, M.D.; CASTRO, J.M. da C.; CALGARO, M.

Contribuições das pesquisas realizadas na Embrapa Semiárido para a cultura da aceroleira Petrolina: Embrapa Semiárido, 2017. 26 p. (Embrapa Semiárido. Documentos, 282). Disponível em:

https://ainfo.cnptia.embrapa.br/digital/bitstream/item/173370/1/SDC282.pdf Acesso em: $21 / 07 / 2019$

VILHENA, A.M.G.F.; AUGUSTO, S.C. Polinizadores da aceroleira Malpighia emarginata DC (Malpighiaceae) em área de cerrado no triângulo mineiro. 
Bioscience Journal, v. 23, n. 0, p. 14-23, 2007. Disponível em:

http://www.seer.ufu.br/index.php/biosciencejournal/article/view/6800/4492 Acesso em: $27 / 07 / 2019$ 